\title{
Prevalence of the different FAB sub type of Acute Myeloid Leukemia related to hematological parameters in Sudanese
}

\author{
Sitelbanat H.Omer ${ }^{*}$, Kordofani $\mathrm{AA}^{2}$, Osman $\mathrm{IM}^{3}$, Musa $\mathrm{OH}^{4}$, Altayb $\mathrm{HN}^{5}$, and Bahaeldin K.Elamin ${ }^{6}$ \\ ${ }^{1}$ Department of Hematology, Al-Gad international college for medical science, Saudi Arabia \\ ${ }^{2}$ Department of Pathology, Faculty of medicine, University of Khartoum, Khartoum, Sudan \\ ${ }^{3}$ Department of Pathology, Faculty of medicine, Alzaiem Alazhari University, Khartoum, Sudan \\ ${ }^{4}$ Fedail specialized hospital, Khartoum, Sudan \\ ${ }^{5}$ College of medical laboratory science, Sudan University of Science and Technology, Khartoum, Sudan \\ ${ }^{6}$ Department Of Microbiology, Faculty Of Medical Laboratory Sciences University Of Khartoum, Sudan
}

${ }^{*}$ Corresponding author: Sitelbanat H.Omer, Department of Hematology, Al-Gad international college for medical science, Saudi Arabia, E-mail: setosman@hotmail.com

Citation: Sitelbanat H.Omer, Kordofani AA, Osman IM, Musa OH, Altayb HN, et al. (2017) Prevalence of the different FAB sub type of Acute Myeloid Leukemia related to hematological parameters in Sudanese. J Hematol Blood Disord 3(1): 102. doi: 10.15744/2455-7641.3.102

Received Date: February 11, 2017 Accepted Date: August 15, 2017 Published Date: August 17, 2017

\begin{abstract}
Background: Acute myeloid leukemia (AML) is a heterogeneous disease. Therefore, various parameters are needed to classify this disease into subtypes. The commonly used method for diagnosis and classification is based on FAB criteria using morphology and cytochemical stains. For some of the categories, immunopheno typing is necessary. The aim of present study is to determine the frequency of various sub types in acute myeloid leukemia using FAB criteria in our Sudanese population. This will aid in the correct diagnosis of acute leukemia and hence proper management of the patients.

Materials and Methods: This is retrospective study conducted at RICH \& Fadial Hospital from January 2014 to December 2016. The total number of subjects was 140 that included both adults and children. The patients were diagnosed on the basis of bone marrow morphology using FAB classification. Cytochemistry was done in all cases, while immunophenotyping was considered only in those cases that were found to be problematic.

Results: Among 140patients, 70 were males and 70 were females with male to female ratio 1:1. The age ranged between 3 years to 101 years with a mean age of 33 years. AML-M3 was the predominant French-American-British (FAB) subtype (29.3\%) followed by M2 (19.3\%), M4 (15\%), M0 (12.9\%), M1 (10\%), M5 (6.5\%), M7 (5\%) and M6 (2.1\%).

Conclusion: The most common FAB subtype observed in our study was Acute promyelocyticleukemia (M3).the incidence of male to female ratio are equally with medium age 33 years old.
\end{abstract}

Keywords: French-American-British (FAB) classification; Acute myeloid Leukemia (AML) subtypes;

\section{Introduction}

Acute leukaemia can be classified in many ways. An ideal classification is one which recognizes real entities with fundamental biological differences. The FAB classification of ALL and AML is based on morphology and cytochemical staining of blasts. However, the recent classification schemes proposed by the World Health Organization (WHO) require the additional evaluation of the leukemic blasts by molecular analysis and flow cytometry. The results of these 4 methods of evaluation (i.e., morphology, staining, molecular analysis, flow cytometry) not only differentiate ALL fromAML, but also categorize the subtypes of acute leukemia.

Acute myeloid leukemia (AML), also known as acute myelogenousleukemia or acute nonlymphocytic leukemia (ANLL). It is a group of neoplastic blood disorders characterized by the proliferation and accumulation of immature haematopoietic cells in the bone marrow and blood. AML accounts for approximately $20 \%$ of acute leukaemias in children and $80 \%$ of acute leukaemia in adults [1]. The incidence of AML progressively increases with age; in adults over the age of 65 years, the incidence is approximately 30 times the incidence of AML in children [2]. The underlying pathophysiology in acute myeloid leukaemia (AML) consists of a maturational arrest of bone marrow cells in the earliest stages of development. The mechanism of this arrest is under study, but in 
many cases, it involves the activation of abnormal genes through chromosomal translocations and other genetic abnormalities [3]. There has not been any previous study addressing adult and children AML in Khartoum City. Accordingly this study was designed with the intent of providing preliminary data on different haematological and FAB subtype of adult and child AML patients in Khartoum City.

The French- American -British (FAB) classification system divides AML into eight subtypes, M0 through to M7, based on the type of cell from which the leukemia developed and its degree of maturity. This is done by examining the appearance of the malignant cells with light microscopy and/or by using cytogenetic to characterize any underlying chromosomal abnormalities. The subtypes have varying prognoses and responses to therapy. Although the WHO classification may be more useful, the FAB system is still widely used.

Eight FAB subtypes which was subsequently revised in 1985 [3]

M0: Undifferentiated acute myeloblastic leukemia

D M1: Acute myeloblastic leukemia with minimal maturation

$\checkmark$ M2: Acute myeloblastic leukemia with maturation (the most common subtype of AML in children)

$\checkmark$ M3: Acute promyelocytic leukemia (APL)

M4: Acute myelomonocytic leukemia (more common in children less than 2 years of age)

M5: Acute monocytic leukemia (more common in children less than 2 years of age)

M6: Acute erythroid leukemia

$\checkmark$ M7: Acute megakaryoblastic leukemia

Subtypes M0 through M5 all start in immature forms of white blood cells. M6 AML starts in immature forms of red blood cells, while M7 AML starts in immature forms of cells that make platelets.

\section{Patients and Methods}

140 diagnosed patients with AML treated at RICH (the only hospital that treats acute leukemias in the region) and fadial specialist Hospital. Khartoum from December 2013 to September 2015 was enrolled in this retrospective study. It included patients of all age groups and both sexes. Exclusion criteria were the absence of complete medicalrecords or bone marrow smears for review. Secondary leukemias (cases with a past history of chemotherapy or radiotherapy or myelodysplasia) and chronic myeloid leukemia in blast crisis were also excluded.

The diagnosis of AML was established according to the standard practice, and was based on peripheral blood and bone marrow morphology and cytochemistry. Immunophenotyping was done where considered essential. Hematological parameters were done on Sysmex KX21 autoanalyzer.

Bone marrow aspiration was done from posterior iliac crest under strict aseptic technique and local anesthesia. A written consent was taken from patients at the time of collection. In every case, 6-8 smears were made; two of them with peripheral smears were stained by Leishman's stain. In addition following cytochemical stains were carried out on peripheral blood and bone marrow smears in each case: Sudan blackB (SBB), periodic acid-Schiff (PAS), myeloperoxidase (MPO). The microscopic morphological examination of AML is based on the recommended criteria.

The project was approved by ministry of health in Khartoum and Hospitals Ethics Committee.

\section{Statistical analysis}

For statistical analysis excel computer program was used to compare between the results of different subtypes of AML

\section{Results}

Of 140 cases, 70 were males and 70 were females with male to female ratio1: 1 . The mean age was 33 years (range 3 years -101 years). 47 cases $(33.6 \%$ ) were up to the age of 18years comprising of 27 males and 20 females and their age ranges between 3 years- 18 years and 93 cases $(66.4 \%)$ were more than 19 years (Figure 1). Their haematological parameters are given in Table 1 . The CBC showed a wide range of variation in hemoglobin concentration and platelets ranging from subnormal to normal. Their Leukocyte count also showed variation from leucopenia to hyper leukocytosis.

\begin{tabular}{|c|c|c|}
\hline Fab Group & $<\mathbf{1 8}$ Years $\mathbf{n} \%$ & $>\mathbf{1 8}$ Years $\mathbf{n} \%$ \\
\hline M0 & $03(23.8)$ & $15(16.1)$ \\
\hline M1 & $05(4.7)$ & $09(9.7)$ \\
\hline M2 & $10(21.3)$ & $17(18.3)$ \\
\hline M3 & $17(36.2)$ & $25(26.9)$ \\
\hline M4 & $07(33.3)$ & $14(15.0)$ \\
\hline M5 & $03(6.4)$ & $06(6.5)$ \\
\hline M6 & $01(2.1)$ & $02(2.2)$ \\
\hline M7 & $03(0)$ & $04(4.3)$ \\
\hline
\end{tabular}

Table 1: Distribution of FAB according to age group $(n=140)$ 


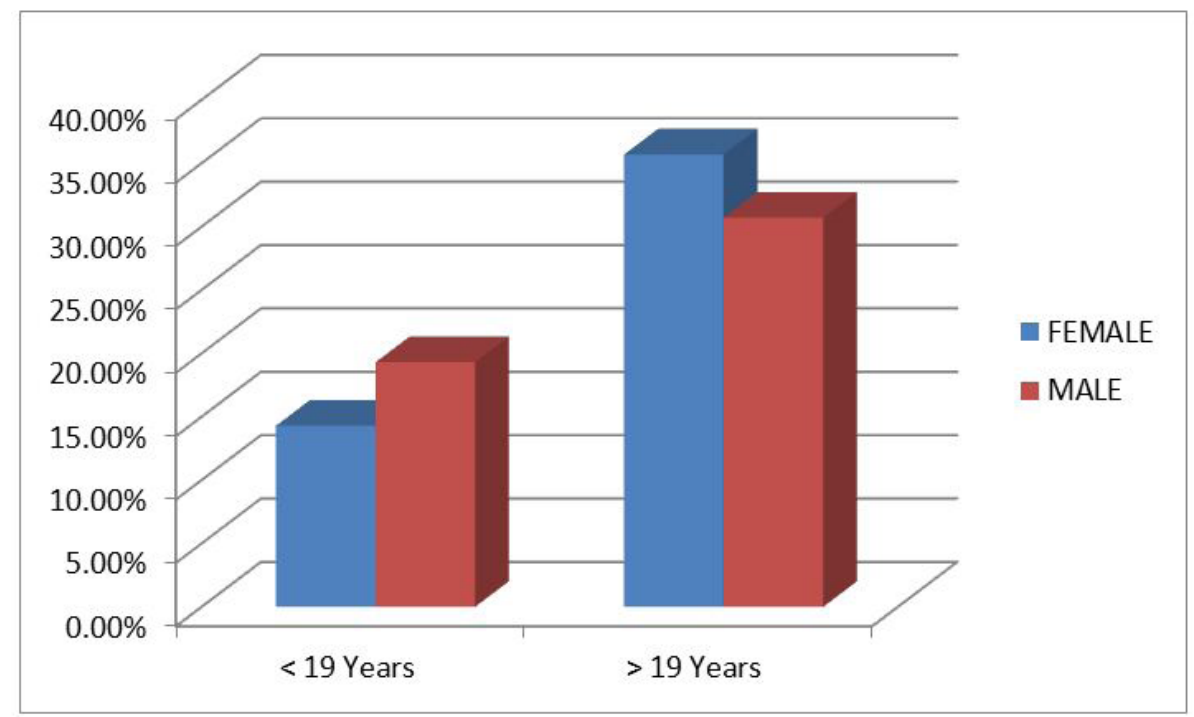

Figure 1: Distribution of gender according to age group

In our study, we found AML (M3 FAB subtypes) to be the commonest comprising 41 out of 140 of total cases (29.3\%). The frequency of various AML subtypes according to FAB classification is given in Figure 2.

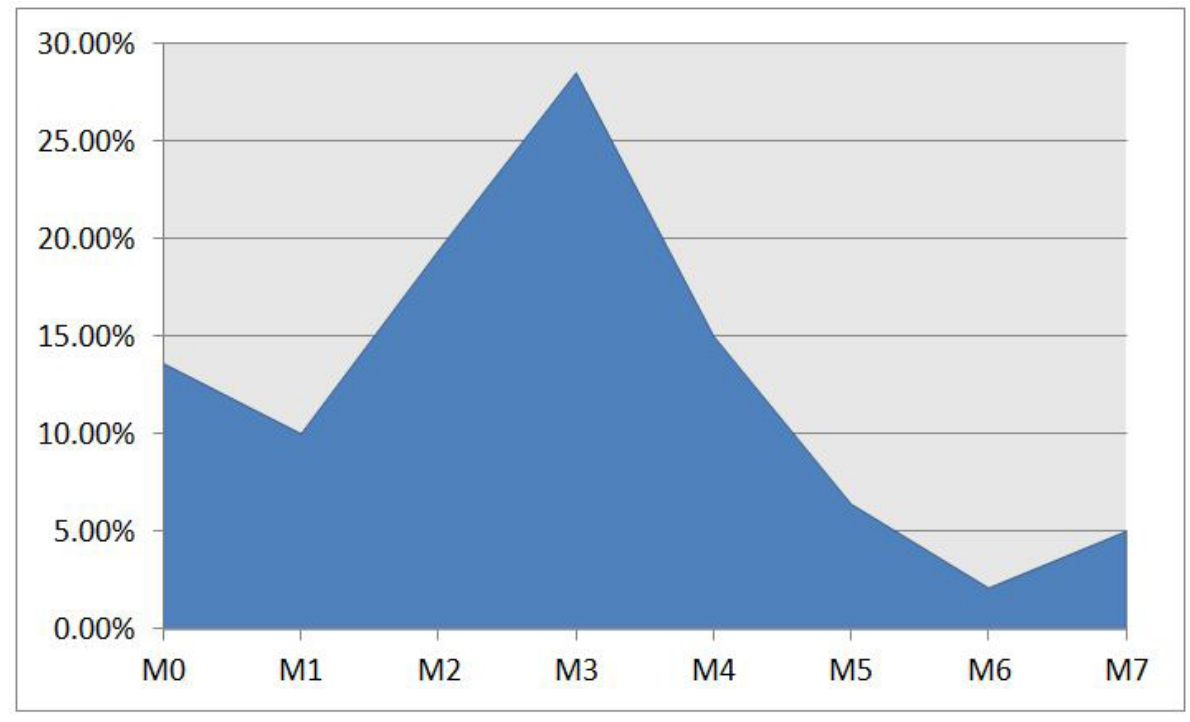

Figure 2: French -American -British (FAB) Sub types in 140 cases of AML

There is no different in pediatrics AML and adult AML in distribution of sub type of AML, which given in Table 1.

Hematological parameter with different FAB sub type is seen in Table 1 and mean of hematological parameter in Table 2.

\begin{tabular}{|c|c|c|}
\hline Parameter & Mean & Range \\
\hline Hemoglobin $(\mathrm{gm} / \mathrm{dl})$ & 8.4 & $2.2-14.4$ \\
\hline White Cell Count $\left(10^{9} / 1\right.$ & 63.39 & $0.6-497.4$ \\
\hline Platelet count $(109 / 1)$ & 48.9 & $1.0-270.0$ \\
\hline
\end{tabular}

Table 2: Hematological parameters in AML patients $(n=140)$

\section{Discussion}

Geographical variations have been described for age and sex distribution as well as FAB (French-American-British classification) subtypes of acute leukemias, possibly due to ethnic and environmental factors. Our study reported Promyelocytic leukemia (FAB-M3) as the most common subtype accounting for $28.5 \%$ of cases followed by M2 with $19.4 \%$ which similar to result in Iraq that reported the M3 subtype was the commonest one account for $26.9 \%$ and followed with M2 with 22.2\% [15]. Arber et al reported M2 as the commonest subtype followed by M5 [4]. Most published data indicate the predominance of M2 as a most common subtype [5]. In figure (1) below the results are compared with other series.

D'Costa GG et al [6] reported M1and M2 as the most common types followed by M4 with no reported cases from M5 and M7 subtypes. Nakase et al showed AML-M4 as common subtype in Australian population compared to Japanese, where AML-M2 is 
common [7]. Kakepoto et al reported M4 to be the commonest followed by M2 [8].

Many of the differences in AML subtypes may be due to the subjectivity of morphologic diagnosis together with variable nature of acute myeloid leukemia

Subtypes, with no real demarcation. Some genetic factors may be responsible for a particular FAB subtypes distribution of AML in our population. The other reason for this discrepancy may be patients of different ethnic group and or geographical variation. Blast cells were seen in peripheral blood in all of our patients with mean of $65 \%$.

Male to female ratio in present study is 1:1, other studies [9] reported 1.5:1. The medium age 33 years similar to that found in thesoutheast of Brazil and studies in Saudi Arabia [9] and Pakistan [10] but lower than the median agereported in western countries where AML peaks in incidence after the $6^{\text {th }}$ decade of life [11] (Table 3).

\begin{tabular}{|c|c|}
\hline Country & FAB subtype \\
\hline United kingdom (UK) [12] & M4 \\
\hline Saudi Arabia (KSA) [13] & M4 \\
\hline Libya [14] & M2 \\
\hline $\begin{array}{c}\text { United states of America (USA) } \\
\text { [5] }\end{array}$ & M2 \\
\hline Australia [7] & M4 \\
\hline Pakistan [8] & M2 \\
\hline Iraq [15] & M3 \\
\hline India [12] & M2 \\
\hline Japan [7] & M2 \\
\hline Our study & M3 \\
\hline
\end{tabular}

Table 3: Incidence of AML subtype in various countries

\section{References}

1. Weinstein HJ (1999) Acute Myeloid Leukemia. Childhood Leukemias. UK, Cambridge University Press 322-35.

2. Bhatia S, Neglia JP (1995) Epidemiology of childhood acute myelogenous leukemia. J Ped Hematol Oncol 17: 94-100.

3. Bennett JM, Catovsky D, Dariel MT, Flandrin G, Galton DA, et al. (1985) Proposed revised criteria for the classification of acute myeloid leukemia: a report of FAB Cooperative Group. Ann Intern Med 103: 620-5.

4. Brunning RD, Matutes E, Harris NL, et al. (2001) Acute myeloid leukaemia:introduction. In: Jaffe ES, Harris NL, Stein H, et al., eds.: Pathology andGenetics of Tumours of Haematopoietic and Lymphoid Tissues. Lyon, France: IARC Press, 2001. World Health Organization Classification of Tumours 3: 77-80.

5. Arber DA, Stein AS, Carter NH, Ikle D, Forman SJ, et al. (2003) Prognosticimpact of acute myeloid leukemia classification. Importance of detection of recurring cytogenetic abnormalities and multilineage dysplasia on survival. Am J ClinPathol 119: 672-80.

6. Douer D, Preston-Martin S, Chang E, Nichols PW, Watkins KJ, et al. (1996) High frequency of acute promyelocyticleukemiaamonglatinos with acute myeloid leukemia. Blood 87: 308-13.

7. Nakase K, Bradstock K, Sartor M, Gottlieb D, Byth K, et al. (2000) Geographic heterogeneity of cellular characteristics of acute myeloid leukemia: a comparative study of Australia and Japan adult cases. Leukemia 14: 163-8.

8. Kakepoto GN, Burney IA, Zaki S, Adil SN, Khurshid M (2002) Long-term outcomes of acute myeloid leukemia in adults in Pakistan. J Pak Med Assoc 52: 482-6.

9. Khalidi HS, Medeiros LJ, Chang KL, Brynes RK, Solvak ML, et al. (1998) The immunophenotye of adult acute myeloid leukemia: high frequency of lymphoid antigen expression and comparison of immunophenotype, French American-British classification, and karyotypic abnormalities. Am J ClinPathol 109: 211-20.

10. Khalid A, Zahid M, Rehman A, Ahmad ZU, Qazi S, et al. (1997) Clinicoepidemiological features of adult leukemias in Pakistan. J Pak Med Assoc 47: 119-22.

11. Mauritzen N, Johansson B, Albin M, Billström R, Ahfgren T, et al. (1999) A single center population-based consecutive series of 1500 cytogenetically investigated adult hematological malignancies: Karyotype features in relation to morphology, age and gender. Eur J Haematol 62: 92-102.

12. Ghosh S, Shinde SC, Kumaran GS, Sapre RS, Dhond SR, et al. (2003) Haematologic and immunophenotypic profile of acute myeloid leukemia: an experience of Tata Memorial Hospital. Indian J Cancer 40: 1-70.

13. Harakati MSE, Al-Momen AM, Ajarim DS, Al-Moharib FI, Al- Theyab A, et al. (1998) Adult acute myeloblastic leukemia: Experience at King Khalid University Hospital. Ann Saudi Med 18: 221-5.

14. Raina V, El-Habbash KI, Tenkovsky (1990) Acute nonlymphoblastic leukemia in adults: experience in Tripoli Libya. Ann Saudi Med 10: 299-302.

15. Al-Allawi NA, Hilmi FA, Yahya HI, Wajdi FT, AlSaleem TI, et al. (1991) Acute myeloid leukaemia: Morphological subtyping and haematologicaldindingsin 214 Iraqi adults. J Fac Med Baghdad 33: 59-71. 


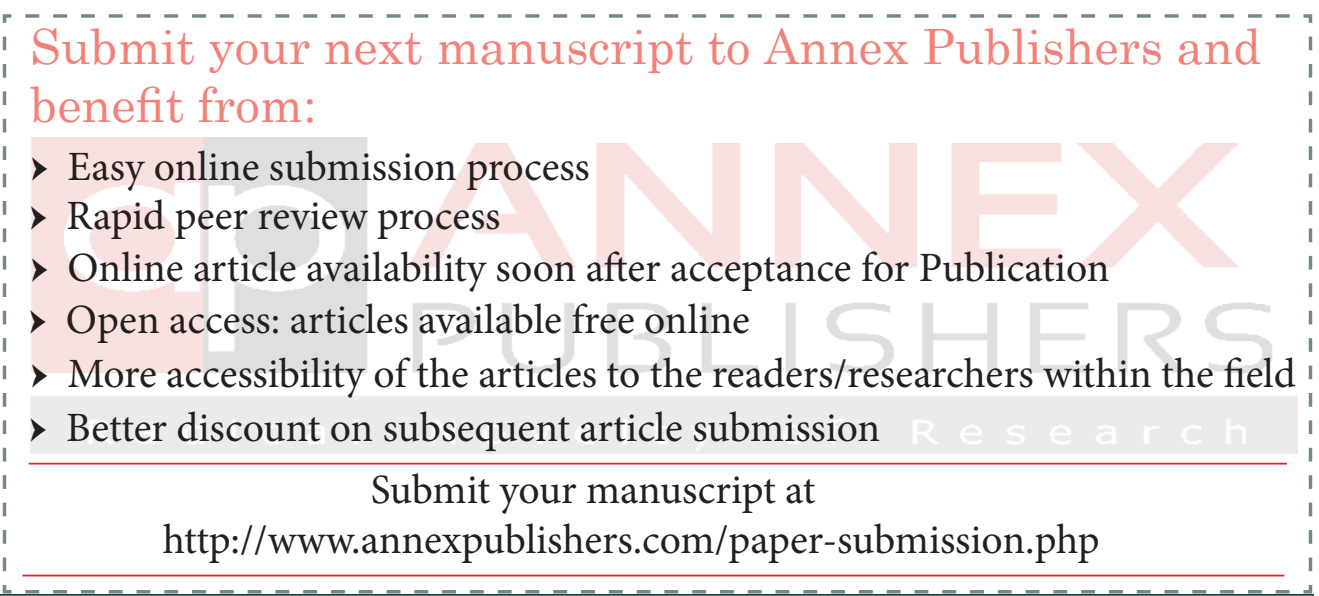

